\title{
Communicative Interaction Features of Actors in the Political Sphere: the Russian-speaking Segment of Facebook
}

\author{
Maria Pilgun and Galina Gradoselskaya \\ National Research University Higher School of Economics, \\ 20 Myasnitskaya Ulitsa, Moscow 101000, Russia.
}

DOI: http://dx.doi.org/10.13005/bbra/1970

(Received: 15 July 2015; accepted: 14 September 2015)

\begin{abstract}
This article presents the results of studies of the communicative interaction of actors in the political sphere in the Russian segment of Facebook. Posts of politically active groups ( $\mathrm{N} 200)$ and individual actors ( $\mathrm{N} 291)$ served as an empirical base, which was updated between January and May 2014. Communicative situation of interaction of politically active actors of the formal-govermental, oppositional and nationalist clusters in the Russian segment of the Facebook social network can be defined as conflictual. Participants of communication consider opponents not as sovereign personality with a certain political and axiological paradigm, but as an object of political opposition. They deny the possibility of finding common basic positions and dialogue. In order to justify the refusal of constructive communication an "enemy image" is created, which is impossible and unworthy to engage in dialogue and try to find a consensus. Thus, social tension increases, degree of social aggression is going up, while the distrust and hatred is heated. Reducing level of aggression can only be possible if actors stop using manipulative strategies, and revive the ability and willingness to use technologies of dialogue by all sides of interaction in the information space.
\end{abstract}

Keywords: Analysis of social networks, Facebook, political communication

This work presents the results of the study of communicative interaction features of actors in the political sphere on Facebook. Interdisciplinary analysis was applied during research. Online political communication is a reflection of offline political communication and thus is extremely intolerant.

Analysis of conflict interaction and communicative aggression in the network environment gains particular importance today. Current Russian-speaking information space is dominated by manipulative techniques aimed at inciting conflicts at various levels. High degree of

\footnotetext{
* To whom all correspondence should be addressed.
}

aggressiveness, which had previously featured Russian media space, during the last and a half year reached its maximum.

Russian-speaking sector of media space which is associated with political communication, is crowded with repressive policies which led to the depressing situation: dominating manipulative techniques, conflict interaction, high level of aggression and, as a natural consequence, rejection of dialogue, the lack of trust to another communicator, and disrespect for someone else's opinion, replacement of traditional forms of communication, which were developed by civilization and regulated by ethical and legal standards.

New media in Russia became caught experts' interest. The transformation of political 
landscape in Russia in 21st century led to increasing importance of social media. The main driver is tremendous growth of number of users. Àccording to the Brend Analytics (2015) 35 million monthly active authors sent 620 million messages were counted in Russia in the first half year 2015. Up to March 2015 the most popular social networking services in Russia are:

a) Vkontakte (vk.com)-53.6 mln users (12 to 64 years).

b) Classmates (odnoklassniki.ru) - 38,75 mln users.

c) Facebook -24,5 mln users.

d) My World (my.mail.ru) -23,7 mln users.

e) LiveJournal -16,4 mln users.

f) Twitter $-7,4$ mln users.

g) (According to materials of Brend Analytics 25 May, 2015).

The choice of Facebook for the analysis of communication interaction of politically active Russian-speaking communities in the media is determined by the fact that Facebook is most often used for professional tasks. Because the Facebook offers a wide range of communication resources for interaction, exchange of information (including photos and videos), participation in communities of interest, and so forth. Equally important is the fact that this social network pays special attention to user's privacy. Also according to researchers of the Berkman Center of Internet \& Society at Harvard University 'unlike their counterparts in the U.S. and elsewhere, Russian bloggers prefer platforms that combine features typical of blogs with features of social network services like Facebook' (Etling and al. 2010, 3)

The article presents the results of studies of the communication interaction of politically active actors at Facebook, which was based on an interdisciplinary analysis for most complete disclosure of syncretism and multidimensionality of on-line interaction.

\section{The aim of the present work}

Analysis of the nature of communicative interaction of actors in the political groups in the Russian-speaking segment of Facebook.

\section{Hypothesis}

Communicative interaction of actors in the political groups in the Russian-speaking segment of Facebook is characterized by a high level of aggression that does not allow them to engage in a dialogue and constructive discussion of contemporary issues.

The material for the study was a database, updated in January - May, 2014, which consisted of 200 politically active groups on Facebook and 291 actors on the Facebook network, a sample of which was made in previously selected political groups.

\section{METHOD}

According to the aim of the study - to investigate the analysis of the nature of communicative interaction of actors in the political groups in the Russian-speaking segment of Facebook, - empirical data collection took place in January - May, 2014.

There is a large number of theories, concepts and methodological platforms which interpret the informational interaction of individuals, groups, systems, and nations, states, cultures and civilizations. Meanwhile, two main approaches are obvious, which allow you to unite different points of view: asymmetrical and symmetrical communication. Hierarchical communication processes in which participants are divided into "leaders" and "followers", "a boss" and "a subordinate", "an adult" and "a child" and so forth, can be attributed to the first approach. Those are repressive forms of communication. The second approach is about symmetric communication, which combines equal partners and is implemented in dialogue form (see. Dzyaloshinsky, Pilgun 2014).

Large volume of research has been devoted to various aspects of network interactions. Lately this interest has focused on studying the dynamics of communication processes in the network environment, the ratio of on-line and offline interactions, influence of social networks on the real life of users. Thus, the material of Englishlanguage Facebook sector can be referred to the Facebook survey by Miller (2013), dedicated to the analysis of the impact of Facebook on the real lives of users. Latent semantic analysis of psychological specific traits of 304 Facebook actors was conducted by Garcia, Sikström (2014). Hall, Pennington and Lueders (2014) explored how a Facebook profile forms an impression. Kruikemeier, Noort, Vliegenthart and Vreese (2014) 
(see also Tufekci and Wilson 2012, Ledbetter and Mazer 2014) devoted their work to the analysis of the influence of the Internet on political activity of the Dutch.

The present study was based on an interdisciplinary analysis to more fully reveal the syncretism and diversity of interaction online. An interdisciplinary approach is the most prevalent in modern research devoted to the analysis of the web environment (see, for example, Blood, 2000; Gorny, 2004; Fuchs, 2014; Lipschultz, 2014; Verboord, 2014; Sauter, 2014).

Formal analysis was carried out in stages, combining quantitative and qualitative methods of analysis. Description of qualitative and quantitative features of content analysis is presented in a sufficient level of detail (White, March, 2006; Krippendorff, 2012 and al.).

Grain clustering in the Russian segment of Facebook revealed three clusters of interconnected communities, each represents a common political attitudes. The first cluster is the community supporting official power structures ("governmental"). The second cluster reflects nationalist views. The third cluster showed communities belonging to the opposition movement.

The communities that appeared to be attributed to all three clusters were subjected to additional analysis and in each of them the most active users were detected. Upon studying 100 of the latest messages in each group 291 active users were identified. Then the users were divided into groups according to the degree of involvement in community activities and their frequency of comment and post writing.

After these procedures a sociolinguistic study of the distinctive and integral characteristics of each type of communication was conducted, both by formal and by communication characteristics. An analysis of communicative behavior (Courtright 2014), linguistic, stylistic and multimedia rhetorical analysis (Handa 2014) was made.

\section{Procedures}

The classification of users by behavior is particularly difficult for modern analysts. Usually one need to choose between the two measures of activity of the actor: his participation in the group or the number of posts. The basis for selection of the most active users ("coverage of groups" vs. "flood") do not contradict, but rather complement each other. The intersection of these parameters allowed us to build a classification of network behavior.

Further sociolinguistic analysis showed that we were dealing with a deliberate division of roles and behavior in the political groups.

Activities in social networks are described by four types of behavior: communication space designers, controllers, scribblers and locally clustered authors.

The material for the study was a database, updated between January and May, 2014:

a) 200 politically active groups in the Facebook social network;

b) 291 Facebook users, a sample which was made in previously selected political groups.

\section{RESULTS}

During the research the politically active groups that exist in the Russian segment of Facebook were clustered, and thus there were identified formal-governmental, oppositional and nationalistic clusters.

The study demonstrates that specific communication in virtual political community on Facebook form a peculiar virtual identities with a clearly defined distribution of functions.

a) Here we can observe the process of standardization of mechanisms to manipulate politically active groups: groups for sale, group occupations, and activities of false entities (advertising, MLM, pyramid investment schemes).

b) A significant part of politically active groups are artificially created and replenished, occupied, sects, etc. (About 50\% of politically active groups are exposed to manipulative practices).

Table 1. Statistical characteristics of the types of network activity

\begin{tabular}{lc}
\hline Type & Proportion of type \\
\hline Designers of communication space & $14,1 \%$ \\
Manipulators & $20,3 \%$ \\
Scribblers & $20,3 \%$ \\
Locally-clustered authors & $45,4 \%$ \\
\hline
\end{tabular}


c) Mechanisms for replenishment of participants in politically active groups vary considerably depending on the type of cluster. At the same time, we noticed activity of professional manipulators in every group, both in common information space, and in separate groups.

d) The formal-governmental cluster prefers primarily formal approach and recruitment of passive mass due to the so-called "garbage" groups.

e) The oppositional cluster stake on the enlisting of activists and prior segmentation of information space for possible future social conflicts.

Formal analysis of verbal behavior revealed no fundamental differences between the official and public actors, and the opposition and

Table 2. Distribution of the different types of actors in different clusters

\begin{tabular}{lccc}
\hline \multirow{2}{*}{ Type of actors on network activity } & \multicolumn{3}{c}{ Type share in clusters } \\
\cline { 2 - 4 } & Governmental & Nationalistic clusters & Oppositional \\
\hline Designers of communication space & 8 & 25 & 31 \\
Manipulators & 7 & 13 & 14 \\
Scribblers & 35 & 16 & 17 \\
Locally-clustered authors & 50 & 46 & 38 \\
Total & 100 & 100 & 100 \\
\hline
\end{tabular}

Table 3. Statistical characteristics of the communicative interaction of actors of various types of network ctivity

\begin{tabular}{lcc}
\hline Type of actors on network activity & Average number of communities & Average number of friends \\
\hline Designers of communication space & 262,7 & 1575,0 \\
Manipulators & 222,9 & 1871,1 \\
Scribblers & 50,7 & 1747,1 \\
Locally-clustered authors & 83,4 & 1350,2 \\
\hline
\end{tabular}

Table 4. Statistical characteristics of communicative interaction of actors of different types of network activity, belonging to different clusters

\begin{tabular}{lccc}
\hline \multirow{2}{*}{ Type of actors on network activity } & \multicolumn{3}{c}{ Average number of messages in groups } \\
\cline { 2 - 3 } & Governmental & Nationalistic clusters & Oppositional \\
\hline Designers of communication space & 25,0 & 65,3 & 106,3 \\
Manipulators & 15,9 & 10,1 & 27,7 \\
Scribblers & 66,1 & 24,7 & 35,4 \\
Locally-clustered authors & 18,7 & 8,7 & 13,9 \\
\hline
\end{tabular}

nationalist clusters. Meanwhile, formal cluster analysis and expert analysis of communicative behavior of actors allowed us to define four groups, depending on their network activity, which may be conditionally denominated as the designers of the communication space, manipulators, scribblers and locally clustered authors: behavior

Typology of users on the network

a) Designers of communicative space are involved in a large number of groups, and write a large number of messages;

b) Manipulators are involved in a large number of groups and write relatively few messages;

c) Scribblers are involved in a small number of groups, write a large number of messages;

d) Locally cluster authors are involved in a small amount of groups (usually located in the same cluster), make relatively few messages. 
Statistical characteristics of actors (N-291) on the type of network activity are presented in Table 1.

Each type has its own qualitative and quantitative characteristics.

\section{Designers of communication space}

Extensive and varied choice of speech, communication and integrated means.

Strategies: ritual, convincing, compelling, provocative tactics of indirect speech influence are often used.

High degree of network activity (involving a large number of groups, making a large number of posts)

\section{Manipulators}

Extensive and varied choice of speech, communication and integrated means.

\section{Strategies}

They use ritual, convincing, compelling, provocative ones. Prevailing: mandatory, provocative. They use implicit and explicit means of expression of intentions, estimates, opinions, and use both direct and indirect means of influencing

Average degree of network activity (involving in a large number of groups, make relatively few messages

\section{Scribblers}

Limited set of speech, communication and integrated means.

\section{Strategies}

Rritual, imperative, prefers mostly explicit means of expression of intentions, estimates and opinions

The average degree of network activity (involving a small number of groups, makes a large number of messages).

\section{Local-cluster authors} integrated means.

Limited set of speech, communication and Strategy

Ritual. They use explicit expression of intention, evaluations, opinions, and direct means of influence.

Low level of network activity involves a small number of groups (usually located in the same cluster) make relatively few messages.

The study defined no differences in communicative behavior of actors in dependence with their political preferences, that is, their belonging to formal governmental, oppositional or nationalist one.

Meanwhile, the actors of different types of network activity have very different verbal communicative behavior. Distribution by types of network activity coincides with the professional skill level of usage of communication resources, as well as technologies and formation management of public opinion in the media. The highest professional skill level in the use of communication resources is shown in the group of communication space designers, and the smallest one in the group of locally clustered authors. Group of manipulators demonstrated average level of communication skills, and scribblers in this parameter follow manipulators, but outperform the group of locally clustered authors (Table 2).

Designers" and "manipulators" tend to be involved in a much larger number of communities than other users - from 200 to 250 (comparing to 50-80 communities, which are average for other groups).

It was also revealed that the designers of the communication space more actively make posts in oppositional and nationalist groups, while scribblers do so in formal governmental groups. This situation explains the quality of the content in the official governmental, oppositional and nationalist clusters (Table 3, 4).

Actors, representing different clusters (formal governmental, nationalist and oppositional) are in conflict interaction, which is reflected in:

a) Communicative and verbal behavior,

b) Choice of communicative web tools,

c) Preference of speech strategies and tactics,

d) Selection of media rhetorical resources.

Communication between members of the formal governmental, oppositional and nationalist clusters differs as follows:

a) Higher aggressiveness;

b) Rejection of dialogue form;

c) Total rejection of a position, which does not coincide with the political views of the actor, etc.;

Communicative interaction of politically active actors in the Russian segment between members of different clusters which reflect the political preferences of the participants can be characterized as antidialogical (see. Prokhorov 2011; Dzyaloshinsky, Pilgun 2014; Pilgun 2015) conflictual: 
a) Communication takes place in the form of an exchange of ideas, remarks, statements, barbs, and not in the form of "dialogue", "conversation with the agreement";

b) Out of two processes, which are typical for social dialogue - mutual attraction (since the need for co-decision is recognized) and mutual repulsion (because differences in the approach to solving the problem are apparent) only the second is used;

c) After the end of the communicative act there is always "winners" and "losers", i.e. the interaction in this case is a hard "struggle". In the course of communication there is no selection of some variants of the decision as the most acceptable, rejection of others and transformation of the third ones. There is no situation in which common approaches and solutions become the winning ones, when results acceptable to all are revealed and achieved common solutions, etc.;

e) there is no premises for normal dialogical relations, which are: recognition of participants' parity in a dialogue, equality of all sides of the interaction for the right to express and defend their positions and proposals for decision-making;

e) there is no intention to avoid conflict, and to use manipulative and provocative technologies. Opponents do not strive to make objective analysis of controversial issues, figure out the genesis of the conflict and find solutions to problems that are acceptable to all parties.

f) there is lack of tolerance in dealing with contentious issues, partners do not consider it necessary to show respect for each other, they do not try to understand the position of the opponent and are not ready to make concessions and compromise, even in solving minor issues to preserve the fundamental base of their position.

\section{CONCLUSION}

The study confirmed the hypothesis: communicative interaction of actors in the political groups in the Russian-speaking segment of Facebook is characterized by a high level of aggression that does not allow them to engage in a dialogue and constructive discussion of contemporary issues.

Politically active actors in the Facebook network are distributed in several clusters in accordance with the political views (formal governmental, nationalist and oppositional clusters).

On the basis of the clustering on graphs a grid sampling was performed and sub-groups were isolated to further identify differential and integral characteristics within clusters and subgroups. We performed the analysis of communicative behavior (Courtright 2014) and linguistic stylistic and multimedia rhetorical analysis of the web content (Handa 2014).

We allocated 4 groups of actors that are characterized by the type of network activity and specificity of use of communication resources (designers of communication space, manipulators, scribblers, locally clustered actors). The distribution of different types of communication varies for different policy clusters (Table 2).

Designers and manipulators are more common in the opposition cluster.

The “designers' most actively make posts in opposition and nationalist groups, while "locally clustered” authors - in the formal-governmental ones. (Table 2).

Communicative situation of interaction of politically active actors of the formal-governmental, oppositional and nationalist clusters in the Russian segment of the Facebook social network can be defined as anti-dialogical and conflictual. Participants of communication consider opponents not as sovereign personality with a certain political and axiological paradigm, but as an object of political opposition. They deny the possibility of finding common basic positions and dialogue. In order to justify the refusal of constructive communication an "enemy image" is created, which is impossible and unworthy to engage in dialogue and try to find a consensus. Thus, social tension increases, degree of social aggression is going up, while the distrust and hatred is heated.

Reducing level of aggression can only be possible if actors stop using manipulative strategies, and revive the ability and willingness to use technologies of dialogue by all sides of interaction in the information space. 


\section{ACKNOWLEDGMENTS}

This publication was prepared within the frameworks of scientific project No. 15-36-12000 powered by the Russian Foundation for Humanities The Program of joint financing of grants of the Russian Foundation for Humanities of the Scientific Foundation of National Research University Higher School of Economics

\section{REFERENCES}

1. Blood, R., Weblogs: A History and Perspective/ Rebecca Blood. URL: http:// w w w.rebec c a blood.net/es s a y s/ weblog_history.html. Brend Analytics - http:/ /br-analytics.ru/, 2000.

2. Courtright, J. A., Observing and Analyzing Communication Behavior. New York, Bern, Berlin, Bruxelles, Frankfurt am Main, Oxford, Wien, 2014.

3. Dzyaloshinsky, I.M., Pilgun, M.A., Technology of dialogue in modern communication space. Theory and history of journalism. 2014; 6: 4254.

4. Etling, B., Faris, R., Palfrey, J., Gasser, U., Kelly, J., Alexanyan, K. , Public Discourse in the Russian Blogosphere: Mapping RuNet Politics and Mobilization. Berkman Center Research Publication No. 2010-11 October 19 2010.

5. Fuchs, Ch., Digital Labour and Karl Marx. New York: Routledge, 2014.

6. Garcia, D., Sikström S., The Dark Side of Facebook: Semantic Representations of Status Updates Predict the Dark Triad of Personality. Personality and Individual Differences. September 2014, 67, 92-96.

7. Gorny, E. Russian LiveJournal: National specifics in the development of a virtual community/ E. Gorny. - 2004. URL: http:// www.ruhr-uni-bochum.de/russ-cyb/library/ texts/en/gorny_rlj.pdf

8. Hall, J. A., Pennington, N.,and Lueders A., Impression management and formation on
Facebook: A lens model approach. New Media \& Society. 2014; 16: 958-982.

9. Handa, C., The Multimediated Rhetoric of the Internet: Digital Fusion. London and New York. 2014; 199.

10. Krippendorff, K., Content analysis. An introduction to its methodology. Third Edition. Los Angeles: SAGE Publications, Inc., 2012.

11. Kruikemeier, S, Noort, G. van, Vliegenthart R. and Vreese, C. H de., Unraveling the effects of active and passive forms of political Internet use: Does it affect citizens' political involvement? New Media \& Society. 2014; 903920.

12. Ledbetter, A.M. and Mazer, J. P., Do online communication attitudes mitigate the association between Facebook use and relational interdependence? An extension of media multiplexity theory. New Media \& Society, 2014; 16: 806-822.

13. Lipschultz, J. H., Social Media Communication: Concepts, Practices, Data, Law and Ethics. New York and London: Routledge, 2014.

14. Miller, D., Tales from Facebook. Cambridge and Oxford, UK: Polity Edition, 2013.

15. Pilgun, M.A., Basic communicative patterns in the Russian network environment. Journal of Psycholinguistics. 2015; 2(24: 23-47.

16. Prokhorov E.P., Introduction to the theory of journalism. Moscow: Aspect Press, 2011. Public Opinion Foundation. http://fom.ru/, 2011.

17. Sauter, T., 'What's on your mind?' Writing on Facebook as a tool for self-formation. New Media \& Society, 2014; 16: 823-839.

18. Tufekci, Z., Wilson, C., Social Media and the Decision to Participate in Political Protest: Observations From Tahrir Square. Journal of Communication, 2012; 62(2): 363-379.

19. Verboord, M., The impact of peer-produced criticism on cultural evaluation: A multilevel analysis of discourse employment in online and offline film reviews. New Media \& Society, 2014; 16: 921-940.

20. White D.M., Marsh, E.E., Content analysis: a flexible methodology. Library Trends, 2006; 1(55): 22-45. 